\title{
Suspendendo a (Des)Crença? Diversidade cultural e religião na Europa contemporânea
}

\section{Suspending (Dis)Belief? Cultural Diversity and Religion in Contemporary Europe}

\author{
Jorge Botelho Moniz ${ }^{1}$ \\ Universidade Nova de Lisboa (Portugal)
}

Recibido: 07-12-18

Aprobado: 11-03-19

\section{Resumo}

Este trabalho analisa as condições de (des)crença numa Europa contemporânea marcada por uma forte e crescente diversidade cultural. Observamos o estado da arte (teórico e empírico) relativamente aos resultados de estudos anteriores sobre o binómio religião-diversidade. Verificamos que, tendencialmente, a diversidade se encontra negativamente associada à coesão e vitalidade religiosas. Os efeitos fragmentadores e relativizadores da diversidade e o crescimento de uma cultura, implícita ou explicitamente, secular são habitualmente apontados como os motivos fundamentais para a fragilização dos laços religiosos, sobretudo dos tradicionais/institucionais. No entanto, a maioria dos investigadores vem resistindo à afirmação dessa correlação negativa, assumindo apenas a deslocação e recomposição da religião em condições de diversidade. Concluímos que se pode concordar com essa asserção; porém, torna-se difícil negar que a diversidade tem efeitos secularizantes, ainda que limitados, na religião, particularmente por conta da emergência e hegemonia dum paradigma imanente de interpretar o mundo.

Palavras-chave: diversidade, religião, secularização, secularidade, Europa.

\footnotetext{
${ }^{1}$ (jobomoniz@gmail.com) Doutor em Ciência Política pela Universidade Nova de Lisboa. Bolseiro da FCT - Fundação para a Ciência e a Tecnologia. Em 2014 foi visiting lecturer em Sciences Po Paris - Universidade de Poitiers. É correspondente nacional da rede científica EUREL da Universidade de Estrasburgo e investigador do CITER - Centro de Investigação em Teologia e Estudos de Religião da Universidade Católica Portuguesa. Tem dedicado o seu trabalho aos temas da religião, secularização, secularismo, modernidade, diversidade cultural, entre outros. Entre as suas principais publicações, destacam-se os livros: Identidades religiosas e dinâmica social na Área Metropolitana de Lisboa (Fundação Francisco Manuel dos Santos, 2019) e A Caminho da República: Imagens que mudaram a face da opinião pública portuguesa (Tenacitas, 2014); o capítulo: "Facing the crisis through charity: A proposal of new humanistic synthesis" (Cambridge Scholars Publishing, 2018); e os artigos "The public funding of religion in post-crisis Catholic Europe" (Ius Ecclesiae, Rivista internazionale di Diritto Canonico, 2016), “A sociologia da religião hoje: secularização(ões), secularismo(s) ou laicidade?" (Política \& Sociedade, 2017), "A regulação da diversidade religiosa pelos estados europeus" (Perspectivas: Journal of Political Science, 2018) e "A culture of secularity? The phenomenon of non-religion in 21st-century Portuguese society and politics” (Journal for the Study of Religions and Ideologies, 2019).
} 


\begin{abstract}
This paper analyzes the conditions of (dis)belief in contemporary Europe within a context of strong and growing cultural diversity. We examine the (theoretical and empirical) state of the art regarding the results of previous studies on the binomial religion-diversity. We observe that diversity is usually negatively associated with religious cohesion and vitality. The fragmenting and relativizing effects of diversity and the growth of an implicit or explicit secular culture are usually referred to as the primary sources for the weakening of religious ties, especially traditional/institutional ones. However, most researchers have resisted affirming this negative correlation, speaking only of displacement and recomposition of religion in diversity conditions. We conclude that this assertion has validity; nevertheless, it becomes hard to deny that diversity has secularizing, although limited, effects on religion, chiefly because of the emergence and hegemony of an immanent paradigm of interpreting the world.
\end{abstract}

Key-words: diversity, religion, secularization, secularity, Europe.

\title{
1. Introdução
}

Nos últimos decénios, as discussões académicas sobre religião têm sido caracterizadas por um confronto teórico entre duas narrativas sobrepostas, embora aparentemente opostas. Por um lado, a conceção de uma perda de relevância social da religião, preconizada pelos defensores das teorias da secularização, na maioria cientistas sociais europeus. Por outro lado, a ideia do regresso (do significado social) das religiões, maioritariamente defendido por teóricos estadunidenses.

No entanto, segundo Casanova (2007: 3), chegou-se a um "ponto morto neste debate", pois a teoria tradicional da secularização adequa-se, relativamente bem, à realidade europeia, mas não à norte-americana, enquanto a narrativa da vitalidade dos mercados religiosos (desregulados) é relativamente eficaz para explicar a realidade dos Estados Unidos da América, mas não a da Europa. Os teóricos afirmam ser necessária uma mudança de rumo das pesquisas sobre esse fenómeno, pois, chegados a este "beco sem saída para o estudo sociocientífico da religião" (Wohlrab-Sahr e Burchardt 2017: 144), o debate sobre a secularização tem-se tornado "infrutuoso" (Casanova 2007: 1, 3).

$\mathrm{Na}$ análise dos fenómenos religiosos contemporâneos, são cada vez mais necessárias novas grades analíticas: economia global, mass media digitais ou migrações estão entre as forças nucleares. Peter Berger (2014), que desde a década de 1990 vem revendo o seu tópico original, entende o pluralismo e 
a diversidade ${ }^{2}$, e não a secularização, como o tema central na sociologia da religião. Também Vilaça et al. (2014) acreditam que, na tentativa de compreender a religião nas sociedades hodiernas, o foco dos investigadores deve estar nos fenómenos migratórios e nas mudanças que, diferentes tradições religiosas e diferentes arranjos Estado-religiões, provocam na alma das distintas sociedades. A mobilidade geográfica e o consequente transnacionalismo cultural (étnico, linguístico ou religioso) desenham um cenário social progressivamente mais diverso e que tem impactos em muitos aspectos da vida cultural e social. Isso é particularmente evidente no mundo Atlântico Norte onde o paradigma de migração mudou abruptamente: sociedades tipicamente de emigração tornaram-se, sobretudo nas últimas décadas, sociedades de imigração ou de migração global (Eco 2002).

Se há algo aparentemente transversal nos diferentes argumentos dos autores citados é a ideia de que a diversidade, além de ser um fenómeno incontornável das sociedades modernas, tem alguma influência sobre a religiosidade. O que é questionável é o tipo de consequências: declínio, vitalidade, nenhum dos dois ou adaptação e recomposição?

Para respondermos a esta pergunta, considerando que não existe uma boa teoria social atual sobre o binómio religião-diversidade, afigura-se-nos mais pertinente e desafiante construir a base duma teoria que, inspirada nas reflexões dispersas do estado da arte, nos permita compreendê-lo mais ampla e profundamente. Para cumprir este desiderato, que tem tanto de ambicioso (pela dimensão que pretende cobrir) como de arriscado (pela parca teorização atualmente desenvolvida), analisaremos, sobretudo à luz da realidade europeia, os argumentos que consideramos mais sustentados teoricamente e mais coerentes empiricamente.

\section{Da diversidade e da tentativa de compreendê-la em relação com o religioso}

O termo diversidade tem a sua etimologia no latim diversitas, procurando dizer variedade ou diferença. É a representação, num determinado sistema

\footnotetext{
${ }^{2}$ No geral, os autores vêm reivindicando uma separação entre os conceitos de pluralismo e diversidade (Vilaça 2006; Berger 2014). O âmago do seu argumento é que o pluralismo é um conceito normativo, enquanto a diversidade é uma noção descritiva. O primeiro, como denuncia o sufixo ismo, é um sistema de valores, instituições ou processos que aceita a diversidade como um valor positivo; o segundo diz respeito, descritiva, empírica e factualmente, ao grau de heterogeneidade cultural duma determinada sociedade ou num mesmo contexto social. Neste contexto, optámos pelo conceito de diversidade. Por um lado, isto deve-se ao facto de considerarmos mais prudente evitar questões normativas, processualistas e filosóficas associadas ao pluralismo ou à pluralização. Por outro lado, isso também se prende com o facto de a diversidade estar, normalmente, associada a perspectivas científicas mais neutrais e, por consequência, metodologicamente mais pacíficas, operando apenas ao nível analítico-descritivo.
} 
social, da multiplicidade de diferenças e similaridades que existem entre os indivíduos ou os grupos que os representam. É a qualidade do diverso (dimensão positiva), por oposição à cultura de grupo, à homogeneização de culturas ou à monocultura (dimensão negativa). A noção de diversidade está, portanto, associada aos conceitos de pluralidade, multiplicidade ou heterogeneidade, dizendo respeito à miríade de ideias, características ou elementos distintos que distinguem os indivíduos sobre um determinado assunto, contexto ou ambiente. É uma expressão incorrigivelmente plural e incontornavelmente associada à multiplicidade de identificações culturais de cada grupo social. Com efeito, a diversidade que queremos analisar é a cultural $^{3}$, pois é a cultura - através da sua capacidade de inserção e adequação do ser ao meio - que explica, dá sentido e agrega as diferentes cosmologias sociais, como as étnicas, religiosas ou linguísticas. Não surpreende que, ao tratarem do tópico da diversidade, os cientistas sociais normalmente o associem à cultura.

Embora a diversidade não seja um fenómeno propriamente recente (Taylor 2007; Berger 2014), com a acelerada globalização da segunda metade do século XX tornou-se, segundo Taylor (2007: 437), irreconhecível para e incomparável com qualquer época histórica anterior. $\mathrm{O}$ mundo contemporâneo tem-se tornado gradualmente mais heterogéneo cultural, religiosa e etnicamente, sendo marcado por uma diversidade inédita de cosmovisões que se multiplicam irrefreavelmente (Taylor 2007).

Esta é, de acordo com o estado da arte, uma marca indelével da modernização. Para Berger (2014: 53), a modernidade e a diversidade estão inelutavelmente cruzadas, pois a primeira leva "necessariamente" à segunda, libertando todos os processos que a estimulam, nomeadamente a urbanização, as migrações em massa, a alfabetização e o desenvolvimento das tecnologias de comunicação. Também para Vilaça (2006: 22) a diversidade tornou-se num dos "traços da modernidade". Por causa do aumento dos fluxos migratórios e da mobilidade geográfica e do progresso dos mass media, as sociedades diversificam-se étnica, religiosa e linguisticamente. Todavia, esta crescente heterogeneidade não é passageira. De acordo com a autora, ela é a nova "norma e não uma mera situação transitória" (Vilaça 2006: 22). Estas perspetivas são corroboradas por outros autores. Martin (2005: 157) diz que a diversidade é uma característica "presente de forma massiva no mundo contemporâneo", Taylor (2007: 300) chama-lhe "supernova" "galopante" da era moderna, Pickel (2017: 290) diz que é um dos "prognósticos seguros para a Europa” e Vilaça et al. (2014: 2) preveem que o seu crescimento se manterá como resultado dos efeitos da globalização.

\footnotetext{
${ }^{3}$ Doravante, sempre que nos referirmos ao termo diversidade, estaremos a fazê-lo à luz da ideia de diversidade cultural. Salvo quando indicarmos o contrário.
} 
Com efeito, os estudos empíricos, estatísticos, sobre tendências demográficas, projeções do crescimento populacional ou dinâmicas migratórias mundiais apontam para profundas mudanças e, consequentemente, para uma crescente complexificação das dinâmicas culturais, religiosas ou étnicas regionais. Por exemplo, o Pew Research Center $(2015,2017)$, nas suas previsões sobre o crescimento populacional e sobre o futuro das religiões mundiais até 2050, mostra o modo como o perfil religioso do mundo está a "mudar rapidamente" (Pew 2015: 5). Isto deve-se, sobretudo, à diferença entre as taxas de fertilidade, ao tamanho das populações juvenis e às conversões religiosas típicas duma era global e plural. Mas também se deve ao número de migrações internacionais. De acordo com o relatório das Nações Unidas sobre a migração internacional de $2017^{4}$, entre 1990 e 2017 a percentagem de migrantes internacionais aumentou, ao nível global, 69\%. Esta é uma tendência crescente, dado que o volume de migrações internacionais cresceu a uma taxa média anual de $1,2 \%$ entre 1990 e 2000 e a uma taxa de $2,4 \%$ entre 2000 e 2017. As regiões consideradas desenvolvidas receberam $60 \%$ do total dessa migração durante a totalidade do período. Outra questão relevante aqui é o número de pedidos de asilo que, em 2015, bateu, ao nível europeu, o número recorde de 1,3 milhões de candidaturas (Pew 2017).

A irreconhecibilidade destes fenómenos ou a sua incomparabilidade com outros períodos históricos, como Taylor sublinha e como já citámos, deve-se ao facto de não estarmos a passar por simples processos de emigração, mas de migração global, e essa diferença, como eloquentemente coloca Eco (2002), é fundamental para compreender o nosso mundo globalizado.

\begin{abstract}
"Ainda é possível distinguir emigração de migração quando o planeta inteiro está a tornar-se o território de deslocações cruzadas? Creio que é possível: como disse, as imigrações são controláveis politicamente, e as migrações não; são como os fenómenos naturais. Enquanto há imigração, os povos podem ter a esperança de manter os imigrados num gueto, para que não se misturem com os nativos. Quando há migração já não há guetos, e a mestiçagem [neste contexto, acrescentaríamos a diversidade e/ou pluralismo] é incontrolável. Os fenómenos que a Europa tenta ainda enfrentar como casos de emigração são, pelo contrário, casos de migração" (Eco 2002: 109-110).
\end{abstract}

Por conta destes eventos globais, o tema da diversidade tornou-se numa das mais "promissoras agendas de pesquisa" (Pollack 2014: 115), sendo um dos "tópicos mais importantes" nas ciências sociais contemporâneas (Doktór 2009: 26). Para isto muito ajudou o facto de os teóricos da secularização terem começado a associá-la aos efeitos da modernidade. O seu argumento básico é o seguinte: a modernidade não leva necessariamente à secularização; porém, conduz inevitavelmente à diversidade (Berger 2014; Vilaça et al. 2014).

\footnotetext{
${ }^{4}$ Cf. "International Migration Report 2017 - Highlights".
} 
Todavia, salvo o caso de Vilaça et al. (2014), cujo interesse de investigação parece centrar-se mais na mutação do religioso em condições modernas e não no seu declínio, os outros teóricos da diversidade parecem marcados pelo estigma da secularização. Para eles, a diversidade leva à "contaminação cognitiva" (Berger 2014: 2) que, por conta dos crescentes contactos interpessoais globais, relativiza e enfraquece os consensos morais; à "diferenciação interna" (Pace 2016: 9) que, quando o contexto se altera, leva as sociedades a transferir a sua complexidade externa para a esfera privada; e à "fragilização mútua" (Taylor 2007: 303-304) das cosmovisões (religiosas ou não religiosas). Não obstante a omissão dum argumento que afirme, explicitamente, a ligação (negativa) do eixo modernidade-diversidade-secularização, esta relação parece presente de forma implícita. Com efeito, se a modernização leva fatalmente à diversidade e se esta, pela concorrência de diferentes cosmovisões, provoca uma contaminação, diferenciação ou fragilização dos valores sociais, então, a diversidade tenderá a enfraquecer, entre outras, as certezas religiosas. Ou seja, a modernização provoca uma diversificação das visões do mundo que, por seu turno, é acompanhada de um enfraquecimento das convicções religiosas.

Esta conclusão pode, porém, parecer simplista se entendida à luz dos efeitos complexos e, por vezes, reversíveis da diversidade na religião. De acordo com Berger (2014: 15), as religiões não estão de forma alguma imunes às consequências da diversidade; pelo contrário, este é "o grande desafio de todas as tradições e comunidades religiosas na era moderna" (Berger 2014: 15). No entanto, como o próprio autor adita, à medida que a diversidade vai extenuando as convicções religiosas vai surgindo uma miríade de opções cognitivas e normativas que, em grande parte, podem ser religiosas. Esta ideia, aparentemente, dicotómica fica bem expressa através da reflexão de Pickel (2017) sobre os processos de secularização e diversidade que marcam as sociedades europeias contemporâneas. Para ele, a diversidade:

“[É] o segundo prognóstico seguro para a Europa (...). [Por conta dele], [a] lém dum crescimento da discussão pública e política em torno da religião, também existe (pelo menos na Europa) uma «perda arrasadora da relevância da religião». Não podemos, por conseguinte, excluir preliminarmente uma reativação da identidade (religiosa) no futuro. No entanto, em face do enfraquecimento dos laços, do conhecimento ou da integrabilidade religiosos, isso parece improvável" (Pickel 2017: 290).

Ou seja, a diversidade parece enfraquecer tendencialmente a religião; porém, também pode ter efeitos positivos sobre ela. Todavia, parece-nos que os autores, pela forma como constroem os seus argumentos - entendem sempre o crescimento da religiosidade, em condições de diversidade, como uma eventualidade -, se aproximam mais da primeira proposição. 
Entender os efeitos atuais da diversidade na religião afigura-se, portanto, como um desiderato difícil. Os autores não advogam mais uma tendência geral, unívoca e determinista. Apesar de mostrarem que a diversidade pode ter consequências perniciosas para a religião, atualmente, tendo em conta a experiência com as várias falácias da secularização (Moniz 2017), eles salvaguardam as suas teses, oferecendo-lhes uma hipótese de relação saudável entre ambos.

A atual postura (prudente e diplomática ou dicotómica e reversível) dos teóricos da secularização, quanto aos efeitos da diversidade na religiosidade, contrasta com as posições mais assertivas assumidas no decorrer da segunda metade do século XX. Nessa época, de um lado, encontramos os teóricos que afirmam que, com a diversificação, as visões do mundo, religiosas ou não, tendem a ser relativizadas e a sofrer uma crise de plausibilidade. Embora por razões diferentes, estes teóricos argumentam, no geral, que os processos de racionalização (Berger 1990 [1967]), societalização (Wilson 1969 [1966]) ou diferenciação (Luckmann 1967) levam a uma autonomização que engloba a diversidade e que é a causa do enfraquecimento das cosmovisões religiosas. Assim sendo, as práticas e crenças religiosas, bem como as instituições que as enquadram, beneficiam dum nível mais elevado de firmeza quando enquadradas, usando o termo bergeriano, numa estrutura de plausibilidade homogénea e partilhada pela maioria das pessoas. Por contraste, sob condições de diversidade e com a consequente desmonopolização das perspectivas religiosas do mundo, a pretensão de legitimidade inquestionável e auto-evidente das comunidades ou instituições religiosas tende a ser desafiada. As organizações religiosas passam a atuar dentro duma lógica de mercado onde também competem com uma pluralidade de cosmovisões seculares (Stolz 2010). Esta competição intra e extra religiosa afeta a credibilidade das perspectivas religiosas do mundo e, por conseguinte, atinge negativamente os níveis de crença ou prática religiosa. De outro lado, os teóricos da economia religiosa ${ }^{5}$ esperam que a participação e o compromisso religiosos sejam influenciados pela oferta de religião. $\mathrm{O}$ seu argumento diz-nos que mais diversidade religiosa (mas também, maior liberdade religiosa) aumenta a participação e empenhamento religioso. Isto sucede, porque a diversidade fomenta a competição. As instituições e comunidades religiosas trabalham mais afincadamente para satisfazer a procura religiosa e, por consequência, as pessoas tendem a ficar mais satisfeitas com o serviço oferecido e a envolver-se mais com o religioso. Ou seja, contrariamente aos primeiros teóricos, a diversidade teria um efeito positivo na religião.

${ }^{5}$ A teoria da economia religiosa, defendida por autores como Laurence Iannaccone, Rodney Stark, Roger Finke, Stephen Warner ou William Bainbridge, diz essencialmente que nas sociedades modernas existe uma procura social permanente por religião, mas que a vitalidade religiosa depende da diversidade de e competição entre firmas religiosas (igrejas ou seitas) em atividade no mercado. 
Não obstante a centralidade destes estudos e autores para o debate dos efeitos da diversidade na religião, este tópico (amiúde sob o vocábulo pluralismo) esteve, até à atualidade, sempre presente implícita ou explicitamente nos trabalhos sobre a secularização. Bruce (2002) ou Taylor (2007) associam, um mais do que outro, o declínio ou a marginalização da autoridade das crenças religiosas, a fragmentação das visões do mundo e a rutura da homogeneidade cultural e religiosa à diversidade social e à pluralização das cosmovisões individuais. Outros autores fazem exercícios semelhantes. Por exemplo, Casanova (1994) analisa a posição das religiões no mundo moderno à luz da diversidade - a condição estrutural da modernidade -; Martin (2005) observa o contexto global de secularização através dum pluralismo competitivo e expansivo; Vilaça et al. (2014) relacionam a modernização e os seus fenómenos de migração internacional, fluidez demográfica e nova economia global com o pluralismo e com as suas múltiplas possibilidades de identificação e pertença; enfim, Norris e Inglehart (2004) correlacionam os níveis de religiosidade dos indivíduos com um índice de pluralismo religioso.

Por causa desta presença, mais ou menos assídua e mais ou menos explícita, da diversidade nos trabalhos dos teóricos da secularização, surgiram vários estudos empíricos que quiseram compreender a correlação diversidade-religiosidade. A existência duma correlação negativa foi tomada como corroboradora das teorias da secularização, enquanto uma correlação positiva sustentaria os pressupostos do modelo da economia religiosa. A literatura sobre o tema cresceu tanto que, nos inícios do século XXI, Chaves e Gorski (2001) fizeram uma grande revisão do tópico através do exame de 193 testes em 26 artigos científicos. Nesse estudo, reportam, sobretudo, a relação tendencialmente negativa ou nula (quase $70 \%$ dos casos) entre a diversidade e a participação religiosa (em qualquer sentido geral). A correlação positiva entre as variáveis não é portanto comprovada pelos seus resultados, salvo quando aplicada a um número limitado de casos.

Outro estudo, o "mais crítico” na opinião de Norris e Inglehart (2004: 97), afirma que todos os resultados de todas as correlações (positivas ou negativas) devem ser abandonados (Voas, Olson \& Crockett 2002). De acordo com Voas, Olson \& Crockett, no início da centúria, não havia provas convincentes de que a diversidade tinha qualquer efeito na participação religiosa. Qualquer variação aleatória no número de casos selecionados determina, segundo eles, graus de correlação diferentes. Ou seja, a relação entre diversidade e envolvimento refletiria apenas a relação matemática entre as medidas de participação e um índice de diversidade, não tendo como base qualquer fator substantivo. Por conta disso, é-nos dito que "todas as provas oferecidas por ambas as partes do debate são agora suspeitas" e que a diversidade "pode não ter qualquer efeito na participação religiosa" (Voas, Olson \& Crockett 2002: 218). Embora 
partilhemos algumas das suas preocupações, julgamo-las excessivas e, como os próprios autores admitem, as provas que reúnem são "altamente circunstanciais" (Voas, Olson \& Crockett 2002: 230). Por conseguinte, os estudos empíricos sobre o impacto da diversidade na religião continuaram.

Norris e Inglehart (2004), de certo modo, em linha com Voas, Olson \& Crockett, mostram que os resultados do seu estudo não apontam para uma grande influência da diversidade na religião. Todavia, admitem que algumas correlações apontam para uma relação forte e significativa entre o primeiro e o grau de participação religiosa dos indivíduos. Esta correlação é praticamente sempre negativa. Contrariamente aos pressupostos da teoria da economia religiosa a "análise multivariada dos dados dum vasto grupo de sociedades não apoia a hipótese de que o pluralismo religioso produz níveis elevados de religiosidade" (Norris \& Inglehart 2004: 230); pelo contrário, as sociedades menos heterogéneas apresentam maiores índices de participação religiosa. Os trabalhos de Doktór (2009) e Pollack \& Pickel (2009) também apontam nesta direção. O primeiro, ao estudar a relação entre a diversidade religiosa e as relações de vizinhança e/ou amizade, conclui que, no geral, a influência da diversidade religiosa é negativa. Os segundos, ao examinarem a correlação entre as relações Estado-religiões e a vitalidade religiosa, concluem, novamente, que os dados empíricos não só não confirmam os pressupostos da economia religiosa, como ainda os contradizem. Com efeito, no seu estudo, as correlações, quando significativas, apontam no sentido contrário da economia religiosa - quanto maior a diversidade, menor a participação religiosa.

Em suma, o debate dos teóricos da secularização sobre o pluralismo e os seus efeitos na religião, tal como todo o debate da secularização, tem sido prolífero, contraditório e inconclusivo. No entanto, conseguimos detetar quatro etapas essenciais. A primeira, desenvolvida mais energeticamente até à década de 1970 e preconizada pelos teóricos da secularização, assevera que mais diversidade significa menos religião. A segunda, nascida em meados da década de 1980 e acompanhada pelos primeiros estudos empíricos mais sistemáticos dos teóricos da economia religiosa, afirma, inversamente, que mais diversidade significa mais religião. A terceira, surgida na primeira década do século XXI, por conta deste debate, é marcada, como acabámos de ver, por uma tentativa de aclaração das duas etapas dicotómicas originais. Os seus resultados não foram conclusivos, apontando em várias direções. Todavia, trouxeram à luz, ainda que fragilmente, a correlação tendencialmente negativa ou nula entre diversidade e religião. A última, que se vive atualmente e cuja reflexão se foi adensando desde a primeira metade da década inicial do século XXI, procura lidar, ainda na aurora da sua adolescência, com a coexistência da diversidade (cultural, étnica ou religiosa) nas sociedades e com os seus presumíveis efeitos na religião. Este tópico surge agora de forma mais premente, por causa das mudanças rápidas 
e globais provocadas pela globalização, pelas migrações transnacionais, pela nova economia global ou pelos mass media digitais. Estes teóricos admitem uma influência maioritária, mas não exclusivamente negativa, da diversidade na religiosidade; porém, isso não significa, necessariamente o enfraquecimento da religião, mas apenas a sua recomposição. Esta é, em certa medida, uma posição intermédia relativamente às teses anteriores. Ou seja, a diversidade, enquanto condição sine qua non da modernidade, já não conduz (contrariamente às teorias da secularização) necessária e fatalmente ao fim da religião, mas também não está normalmente associada ao seu desenvolvimento positivo (contrariamente à teoria da economia religiosa). Apesar de a diversidade trazer consequências para a religião (contrariamente ao que Voas, Olson e Crockett alegam) estes efeitos tanto podem significar um enfraquecimento como uma revitalização.

Pela inexatidão das teses clássicas da secularização e da economia religiosa, relativamente à diversidade, e pela experiência, altamente criticada, de desenvolvimento de teorias unívocas, universalistas e deterministas (tanto numa direção como noutra), a posição política e cientificamente correta passou a ser uma intermédia, semelhante à dos teóricos da quarta etapa elencada. Para se contornarem eventuais críticas, aceita-se a religião como uma espécie de constante antropológica que nenhum processo da modernidade consegue enfraquecer, mas apenas reconfigurar. Mas isto não será apenas um processo dialético hegeliano? Ou seja, será que estamos a passar duma tese (secularização), para uma antítese (economia religiosa), até uma mera síntese (posição intermédia entre o enfraquecimento da religião e a sua revitalização) sobre os efeitos da diversidade na religião? Por que razão hoje os autores (como Berger ou Pickel) afirmam apenas implícita e tenuemente que a diversidade pode ter um impacto negativo na religião, mesmo quando os seus estudos apontam nesta direção? Dadas as profundas alterações globais que vivemos, em que medida podemos continuar a estudar os efeitos da diversidade na religião à luz de pressupostos teóricos das décadas de 1960 ou 1980? Como poderá a diversidade tornar-se numa agenda de pesquisa promissora se nada mais for do que a negação da negação (na perspetiva dialética de Hegel)?

\section{Diversidade e as suas consequências para o religioso: a suspensão da (des)crença?}

Mesmo em discussão direta com alguns do principais teóricos mundiais como Enzo Pace, Monika Wohlrab-Sahr, Steve Bruce, Gert Pickel ou Marian Bruchardt - que têm preocupações com a questão do secular e da diversidade nos seus trabalhos, a tentativa de explicação dos impactos da diversidade na religiosidade nem sempre é clara, muito menos consensual. No entanto, uma das pistas, normalmente, menos divergentes é Charles Taylor. 
No seu livro $A$ Secular Age, por nós já citado inúmeras vezes, o filósofo canadiano diz que a diversidade - o "mundo plural" ou "pluralismo galopante" (Taylor 2007: 300) como o designa -, traz uma multiplicação de posições (crentes e não-crentes) que se debatem e que, por consequência, se fragilizam. Esta cultura fraturada, à qual chama de "nova" (297 ss), disseminou-se nas sociedades, especialmente nos finais do século XX, tendo-se tornado numa das principais características das sociedades do século XXI. A diversidade é, portanto, uma parte importante da resposta sobre como a religião é atualmente diferente. Na linha do Sacred Canopy (1967) ou do Heretical Imperative (1979) de Peter Berger, Taylor admite que em contextos homogéneos, ao nível social ou religioso, as dúvidas sobre os nossos princípios ou crenças não surgem tão facilmente. Todavia, nas sociedades modernas - marcadas pelo tal pluralismo galopante, pela retirada de elementos religiosos da vida pública e pela sua substituição por outros associados a uma cultura pública (secular) e pelo aparecimento do indivíduo secular, que considera que os seus próprios valores e identidades básicas não têm ligação com os tradicionalmente manifestados pela religião - dificilmente se consegue manter a concepção geral de que a crença divina é central para a ordem social. Pelo contrário, em alguns meios o secular tornou-se a "solução por defeito" (Taylor, 2007: 12-13, 531, 556).

O efeito fragilizador da diversidade, que Taylor admite estar presentemente no seu máximo, terá como resultado frequentemente "inevitável” (Taylor 2007: 532) o recuo da religião no espaço público. Apesar de reconhecer, inspirado no trabalho de Casanova (1994), que o religioso manterá um certo protagonismo no espaço público, Taylor entende que a competição religioso-secular é um terreno desnivelado e com predomínio de princípios duma ordem moral moderna secular (por exemplo, a democracia ou os direitos humanos). Assim sendo, para Taylor (2007: 437) "a proporção de crença é mais pequena e a de descrença é maior do que alguma vez foi”.

Quer concordemos mais ou menos com esta posição devemos, primeiramente, entendê-la no contexto do mundo Atlântico Norte que é, essencialmente, onde se concentra a proposição tayloriana. Em segundo lugar, devemo-nos concentrar nas pistas de investigação que nos oferece, nomeadamente no que respeita ao reconhecimento de certos elementos da diversidade que podem ter impactos no religioso. Um desses indícios pode ser encontrado na conceção de Taylor (2007: 531) que diz que, em condições modernas, a força das crenças depende muito mais do que no passado das "intuições poderosas que os indivíduos radiam uns para os outros". As formas institucionais e centralizadas de religião são portanto menos capazes do que no passado de influenciar as ações dos indivíduos. Este argumento foi partilhado diretamente comigo, em particular, por Enzo Pace ou Steve Bruce. Por um lado, o primeiro defende que isso pode ser justificado através duma 
abordagem sistémica luhmianna (Luhmann [1998] 2013) que vê a religião como um sistema de relações estabelecidas com um determinado meio. $\mathrm{O}$ argumento básico é que, pela coincidência dos fenómenos de diferenciação funcional e de regulação ou controlo da religião, as suas formas institucionais tradicionais sofrem uma perda relativa de relevância social. Este argumento é desenvolvido mais profundamente em Pace (2017). Por outro lado, o segundo assevera que essa diminuição do significado social da religião institucional e tradicional deriva da falta de consenso social, uma das suas principais bases de sustentação, provocada pela diversidade. O proselitismo religioso, de nível macro (institucional), torna-se cada vez menos capaz de cativar os indivíduos, no sentido da conversão ou conservação de fiéis. Por seu turno, a contínua afirmação societal (através de interações quotidianas), de nível micro, passa a ser a sua forma mais influente de persuasão. Contudo, considerando o grau de secularidade das sociedades ocidentais modernas essa persuadição passa, não raras vezes, a ser efetuada em torno de valores e práticas seculares. Bruce explica isto de forma não tão direta em alguns dos seus trabalhos $(2002,2006$, 2011, 2017).

Estas ideias são devedoras da obra The Social Construction of Reality (1966) de Berger e Luckmann e da ideia de que a realidade quotidiana, considerada autoevidente e dominada por princípios e rotinas pragmáticos, obriga a uma suspensão da crença (religiosa). Com a pressão exercida pela hegemonia dos princípios seculares, as forças sagradas são gradualmente removidas das reservas de conhecimento disponibilizadas socialmente, tornando-se mais dificilmente adquiríveis. À medida que o religioso é afastado do quotidiano e das confirmações face-a-face, mais difícil se torna retê-lo. O estudo de Teixeira (2012), de certo modo, elucida-nos sobre o modo como em Portugal estas confirmações são relativamente raras no espaço público. Em 2011, por um lado, uma grande parte das pessoas (cerca de 50\%), mesmo as religiosas, dizia não falar de assuntos ou temas religiosos e, por outro lado, a maioria dos que o faziam (cerca de 30\%) limitavam-nos à esfera privada, familiar. O facto de "quase metade" das pessoas (religiosas ou não religiosas) não considerar os assuntos religiosos "cativantes" (Dix 2013: 68) no seu quotidiano faz com que, nesta era secular, a decisão de transitar da realidade quotidiana (por defeito, secular) para "províncias de significado finito", como a experiência religiosa, seja "extrema", segundo Berger e Luckmann (1966: 37, 39). Pelo peso pessoal e social inerente a essa mudança, a vida quotidiana torna-se menos permeável à influência do religioso.

Este argumento é também subsidiário da tradição bergeriana do The Sacred Canopy. Em especial da asserção de que a diversidade (e o consequente advento da competição entre diferentes esferas sociais e, posteriormente, o desenvolvimento da secularidade) relativiza qualquer corpo de crenças 
religiosas, minando a inquestionabilidade das suas estruturas de plausibilidade. Assim, os crentes desenvolvem uma consciência (mesmo que falsa) de que são a minoria cognitiva. Isto afigura-se mais evidente em condições modernas, porque, tal como diz Berger (1979), embora o crente contemporâneo seja muito semelhante ao da Idade Média, existe uma diferença fundamental entre ambos. Ela reside no facto de, diferentemente do segundo, o primeiro não conseguir evitar a ideia e o conhecimento de que existem (muitas) outras formas de crença (religiosa ou não). Esta perspetiva relativizadora ou cética relativamente às crenças dos outros é entendida como um pressuposto praticamente inevitável das sociedades plurais. As crenças tornam-se mais vagas, deixando de ser centrais nas ações da vida quotidiana dos indivíduos.

Talvez por isso, segundo dados de 2007 do Eurobarómetro, os valores culturais que os europeus menos enalteciam, em média (9\%), eram os valores e crenças (filosóficos e religiosos), apresentando taxas muito baixas até entre alguns países com maiores índices de religiosidade: Polónia com 4\%, Portugal com $8 \%$ e Itália com 10\%. Estas teorias talvez possam ajudar a explicar também por que razão, em 2008 e 2012, dentre os valores pessoais dos europeus, a religião tenha sido em média (7\% em 2008 e 5\% em 2012) o menos considerado. Os outros valores, típicos da ordem moral moderna secular, como a democracia, o Estado de direito, a liberdade, a paz ou os direitos humanos, encontravam-se destacadamente à frente dos religiosos. Isto sucede igualmente com o segundo enunciado, típico de sociedades modernas com elevada diversidade, menos considerado pelos europeus - o respeito por outras culturas. Além disso, neste campo, houve um decréscimo geral durante o período de análise em alguns dos países mais religiosos, por exemplo: Portugal desceu de 4\% para 3\%, a Polónia de $14 \%$ para $8 \%$, Itália de $5 \%$ para $4 \%$ e Espanha de $5 \%$ para $3 \%$.

A ideia de que a diversidade ajuda à perda de plausibilidade da religião no espaço público também ecoa na opinião negativa da maioria dos indivíduos desses países ${ }^{6}$, nomeadamente quanto à influência que os líderes religiosos devem ter no modo como os eleitores votam em democracia (média de $79 \%{ }^{7}$ ) ou quanto à sua influência relativamente a decisões governamentais (média de $70 \%{ }^{8}$ ). Mas

\footnotetext{
${ }^{6}$ Para a nossa análise escolhemos, com base em critérios amplos e objetivos, tal como exige o rigor científico, um grupo de seis países - Áustria, Eslováquia, Espanha, Itália, Polónia e Portugal. O primeiro prende-se com o facto de todos os países terem separação Estado-religiões. O segundo concerne à sua tipologia de relacionamento Estado-religiões, onde é permitido, legalmente, ao Estado um tratamento diferenciado das várias igrejas e comunidades religiosas. Em terceiro lugar, a nossa escolha foi baseada na sua condição sociorreligiosa - apenas países de maioria católica apostólica romana. Por fim, os países selecionados são todos europeus, fazendo parte da região que mais mudanças tem vivido ao nível dos fluxos migratórios.

${ }^{7}$ Dados do EVS - European Values Survey de 1999 relativos à pergunta "Os líderes religiosos não devem influenciar o modo como as pessoas votam em eleições" e à resposta "concordo ou concordo fortemente". Os valores por país foram os seguintes, em ordem crescente: Espanha 70,9\%; Eslováquia 74,1\%; Itália 78,9\%; Portugal 81,4\%; Áustria 84,7\% e Polónia 85,4\%.

${ }^{8}$ Dados do EVS de 1999 e 2008 relativos à pergunta "Os líderes religiosos não devem influenciar
} 
também ecoa na resposta positiva no concernente à adequação de políticos para exercer cargos públicos, mesmo não acreditando em Deus (média de 63\% ${ }^{9}$ ).

Steve Bruce, um autodenominado teórico da secularização convicto é, atualmente, um dos autores menos consensuais dentro desta teoria; porém, concordamos com Martin (2017: 7) quando diz que, se sustentados, os seus argumentos podem ser muito úteis para quem estuda a secularização. Neste campo, um dos contributos mais originais de Bruce tem sido a sua ênfase na diversidade e a sua inovação relativamente à versão original de Berger (1990 [1967]) - from sacred canopies to golf umbrellas (Bruce 2018). Com efeito, ele tem sido um dos autores que, mais recente e sistematicamente, tem procurado entender o binómio diversidade-religião, recorrendo amiúde às teorias clássicas supracitadas, mas sempre com o cuidado de as atualizar.

Desde cedo que Bruce parte a sua investigação de duas premissas fundamentais: i) as sociedades ocidentais são, por conta das migrações internacionais, da expansão da unidade política e da fragmentação das culturas religiosas dominantes, locais culturalmente diversos; e que ii) estas mudanças estruturais transformam a psicologia social. As mutações são consequência dos processos de diferenciação social e estrutural (Bruce 2002), descritos por Luhmann; da afirmação e hegemonia de princípios seculares como a igualdade e a liberdade que visam "substituir os religiosos" (Bruce 2014: 192); dum esvaziamento da religião no espaço público, nomeadamente ao nível do "controlo das interações quotidianas" (Bruce 2011: 37), elencadas por Berger e Luckmann, e, por conseguinte, duma agudização da "crise" (Bruce 2006: 37) das suas estruturas de plausibilidade, relatada por Berger; e duma certa relativização das crenças, pois a diversidade e a competição entre cosmovisões religiosas dificulta que alguma se assuma como a verdadeira (Bruce 2002, 2011, 2017). Talvez por isso apenas a minoria (em média, menos de um quarto) dos indivíduos dos países selecionados consiga afirmar que existe apenas uma religião verdadeira ${ }^{10}$ e que a religião é o seu valor cultural e pessoal mais querido. Esta tem sido uma tendência decrescente, nomeadamente por comparação às dimensões trabalho, família, amigos e conhecidos ou atividades de lazer ${ }^{11}$.

decisões governamentais" e à resposta "concordo ou concordo fortemente". Os valores por país foram os seguintes, para 1999, em ordem crescente: Itália 67,8\%; Eslováquia 70,6\%; Espanha 73,2\%; Portugal 79,0\%; Áustria 79,9\% e Polónia 81,4\%. Os valores para 2008 foram os seguintes: Portugal 52,0\%; Eslováquia 60,4\%; Itália 66,1\%; Áustria 67,8\%, Polónia 70,0\% e Espanha 71,5\%.

${ }^{9}$ Dados do EVS de 1999 e 2008 relativos à pergunta "Os políticos que não acreditam em Deus são inadequados para cargos públicos" e à resposta "discordo ou discordo fortemente". Os valores por país foram os seguintes, para 1999, em ordem crescente: Eslováquia 52,6\%; Itália 64,2\%; Espanha 64,7\%; Polónia 66,0\%; Áustria 68,6\% e Portugal 68,8\%. E em 2008: Polónia 55,7\%; Áustria 56,5\%; Portugal 59,3\%; Eslováquia 60,3\%; Itália 63,5\% e Espanha 71,0\%.

10 Segundo dados de 2008 do EVS, na resposta positiva ao enunciado "apenas uma religião oferece alguma verdade". Por país, os resultados foram os seguintes, por ordem crescente: Áustria 9,0\%; Itália 21,3; Eslováquia 23,4; Espanha 26,9\%, Polónia 30,3\% e Portugal 34,3\%.

11 Segundo dados de 1999 e 2008 do EVS, na resposta à pergunta "Quão importante é na sua 
O resultado disto tudo é, segundo Bruce (2014), a secularidade; isto é, um mundo no qual a religião gradualmente vai tendo menos relevância nas diferentes esferas sociais, onde o consenso e a autoridade em torno de valores e práticas seculares são maiores e onde o isolamento religioso, o tal trânsito para províncias de significado finito, tem um custo social muito alto e que a maioria das pessoas não está disposta a pagar. Há, de certo modo, uma suspensão (voluntária ou direcionada) da crença em valores religiosos, transcendentais, e, a contrario sensu, uma suspensão da descrença ${ }^{12}$ nos valores seculares, imanentes, que passam a ser aceites num sentido catártico - como uma libertação de sentimentos e práticas repressoras -, tornando-se na norma destas sociedades marcadas pela secularidade.

Segundo o argumento, o religioso deixa não só de ser reafirmado através da vida quotidiana, como também diminui a sua influência nos ciclos de vida das próprias comunidades (nascimentos ou casamentos). Por exemplo, em Portugal, o número de casamentos religiosos diminuiu (maioritariamente por conta dos casamentos católicos), entre 2007 e 2015 , quase $50 \%{ }^{13}$, correspondendo apenas a $36 \%$ dos casamentos realizados no país, enquanto em 2007 correspondia aproximadamente a 48\%. Em Espanha sucede algo de semelhante. Em 2007 os casamentos religiosos correspondiam a 55\% dos casamentos celebrados no país, mas em 2015 já só correspondiam a pouco mais de $30 \%{ }^{14}$. Em Itália também se assiste a um fenómeno relativamente idêntico. Mesmo ao analisarmos um período de tempo mais curto (2008-2014), verificase que a percentagem de casamentos religiosos diminuiu de $72 \%$ para menos de $55 \%{ }^{15}$. Outros dados, referentes por exemplo à celebração de batismos, também apresentam uma diminuição desde o início do século XXI. Sem contar com a variação do número de nascimentos em cada país, na Áustria ${ }^{16}$ houve uma diminuição de $11 \%$ entre 2003 e 2015 , em Espanha ${ }^{17}$ uma de quase $30 \%$ e em Portugal de $37 \%$ entre 2000 e $2012^{18}$.

Bruce $(2014,2017)$ tem algumas ressalvas quanto aos efeitos da diversidade na religião. Primeiro, porque considera improvável a disseminação

vida?" e aos enunciados "religião" e "muito importante". Por país, os resultados foram os seguintes em 2008, por ordem crescente: Espanha 15,5\% (aumento de 0,6 relativamente a 1999); Áustria 17,7\% (diminuição de 3,7\%); Portugal 24,9 (diminuição de 3,3\%); Polónia 31,1\% (diminuição de 13,8\%); Itália 32,4\% (diminuição de 0,6\%) e Eslováquia 33,5\% (aumento de 6,8\%).

${ }^{12}$ Este termo foi cunhado pelo poeta britânico Samuel Taylor Coleridge em 1817, com a publicação da sua obra Biographia literaria.

${ }^{13}$ Cf. Pordata (2007-2015), indicador: "Casamentos entre pessoas do sexo oposto: total e por forma de celebração".

${ }^{14}$ Cf. Instituto Nacional de Estadística, indicador "\% bodas de España 1976-2016".

${ }^{15}$ Cf. Istituto Nazionale di Statistica, indicador "\% matrimoni, separazioni e divorzi 2008-2014".

${ }^{16}$ Cf. Katholische Kirche Österreich, indicador "Kirchenstatistik 2016 Eintritte, Wiedereintritte, Austritte, Taufen".

${ }^{17}$ Cf. Conferencia Episcopal Española, indicador "Evolución de la actividad litúrgica de la Iglesia Católica", 2008-2014.

${ }^{18}$ Cf. Anuário Estatístico da Igreja, 2012.

Araucaria. Revista Iberoamericana de Filosofia, Política, Humanidades y Relaciones Internacionales, año $21, \mathrm{n}^{\circ} 42$. Segundo semestre de 2019. Pp. 109-132. ISSN 1575-6823 e-ISSN 2340-2199 doi: 10.12795/araucaria.2019.i42.06 
dos processos da modernização a todas as sociedades do mundo e, segundo, porque coloca a possibilidade de haver forças compensatórias no paradigma da secularização - a defesa ou transição cultural. Contudo, elas devem ser apenas entendidas como exceções temporárias e não como uma reversão no processo de secularização. Para Bruce (2002, 2011, 2014, 2017), em sociedades modernas onde haja uma certa paz cultural, ainda que a marginalização da religião possa ser uma consequência involuntária de Estados modernos que se ajustam à diversidade, não há motivos para esperar que a secularização não seja irreversível. Além disso, segundo o argumento, estas consequências serão primeira e mais fortemente sentidas nas sociedades ocidentais democráticas com maiores índices de diversidade (Bruce 2017, 2018).

Como vimos, esta é também a opinião de Pickel (2017), quando nos diz, ainda que com algumas reservas, ser improvável que o religioso saia fortalecido de sociedades fortemente diversas ao nível cultural. Todavia, esta parece ser uma posição relativamente disseminada no debate atual sobre a secularização, visto que vários autores citam diferentes efeitos negativos da diversidade na religião: desde a indiferença (Quack \& Schuh, 2017), à suspeição (Graham, 2017), ao silenciamento (Woodhead, 2012), à incerteza (Pollack \& Rosta, 2017) até ao seu perecimento (McCaffree, 2017). Talvez por isso Bruce (2018) tenha recentemente criticado a retratação de Berger, considerando-a desnecessária.

Com efeito, desde os meados da década de 2000 que Berger vem, explicitamente, revendo a sua posição relativamente aos efeitos dos processos da modernidade, nomeadamente da diversidade, no religioso:

"O que não entendi quando comecei (...) foi que o que mudou não foi necessariamente o quê da crença, mas o como da crença. O que o pluralismo e as suas dinâmicas psicológicas e sociais trouxeram foi que a certeza se tornou mais difícil de alcançar. É a isso que chamo o como da crença. É mais vulnerável. (...) Não estou a dizer que o pluralismo é exclusivamente hodierno, mas acho que a modernização intensificou este processo, tanto em profundidade como em alcance (...). Argumentarei que a modernidade, muito provavelmente, mas não inevitavelmente, leva ao pluralismo, uma pluralização de cosmovisões, valores, etc., incluindo a religião (...)”. (Berger 2006: 153-154) (destaque nosso).

"Estava bastante correto ao afirmar que a modernidade produz pluralismo, mas o pluralismo não produz necessariamente secularidade. O que ele produz, quase inevitavelmente, é uma situação em que nenhuma cosmovisão é inquestionável, de modo que os indivíduos têm de escolher entre as diferentes cosmovisões oferecidas. Contudo, muitas dessas escolhas podem ser religiosas - e, de facto, são-no na maioria do mundo contemporâneo." (Berger 2011: 99, apud Bruce 2018: 105-106).

O grande ponto de discórdia entre Bruce e Berger é que, enquanto o primeiro considera que a diversidade conduz inevitavelmente a um mundo de

Araucaria. Revista Iberoamericana de Filosofía, Política, Humanidades y Relaciones Internacionales, año $21, \mathrm{n}^{\circ} 42$. Segundo semestre de 2019. Pp. 109-132. ISSN 1575-6823 e-ISSN 2340-2199 doi: 10.12795/araucaria.2019.i42.06 
maior indiferença religiosa, o segundo vê a diversidade como uma multiplicação de escolhas sociais não necessariamente seculares.

Para Berger (2014), por um lado, os teóricos da secularização estavam certos ao analisar que a modernização desenvolve um discurso secular influente que, como marca da era secular, assume uma posição dominante na sociedade e na mente das pessoas. Por outro lado, estavam errados ao pressupor que este discurso secular expulsaria as cosmovisões religiosas, assumindo um predomínio total sobre as definições da realidade e sobre as orientações valorativas. Houve, segundo o autor, uma subestimação do religioso por parte dos teóricos da secularização ou da secularidade, muitos deles já citados na secção anterior, relativamente à exclusividade, supremacia ou hegemonia do secular. Além disso, terá havido uma subestimação no concernente à capacidade dos indivíduos para viver em distintas esferas da realidade, religiosa e secular, alternando entre ambas (Berger 2014: 112). Apesar de a modernidade ter efeitos secularizantes - consubstanciados essencialmente na emergência dum padrão imanente de interpretar o mundo, tipicamente tayloriano -, essas consequências são limitadas. Ou seja, os princípios religiosos, as províncias de significado finito, descritas por Berger e Luckmann (1966), e os rituais religiosos conservam o seu fundamento. A religião e a secularização não são, portanto, formas mutuamente excludentes de encarar a realidade, mas abordagens complementares. Há uma diversidade da mente, espelhada nos comportamentos das interações quotidianas, que se reflete numa ação recíproca entre o religioso e o secular - um tipo de linguagem híbrida que pode agregar os dois. Para Berger (2014), este é o próprio significado da diversidade das cosmovisões - a subsistência duma pluralidade de discursos religiosos e seculares não estanques e igualmente legítimos na psique e nas práticas dos indivíduos.

A título exemplificativo, podemos citar o número significativo de pessoas que, em média, nos países selecionados, considera Deus $(50 \%)$ e a religião (63\%) relevantes para a condução das suas vidas, recorre a serviços religiosos (66\%), retira conforto ou força da religião $(67 \%)$ ou se considera religiosa $(77 \%)^{19}$. A manutenção da relevância dos funerais religiosos em todos os países selecionados ou da instrução religiosa (nas escolas públicas e na catequese) em Portugal, mesmo entre não crentes $(33,5 \%)$ e crentes sem religião $(56,4 \%)$ (Dix 2013: 69), e a tendência geral de crescimento dos casamentos religiosos nãocatólicos em Portugal ${ }^{20}$, dos batizados na Eslováquia ${ }^{21}$ e de ambos (incluindo o casamento católico) na Polónia ${ }^{22}$, mostram também como a opção religiosa é plausível e legítima na era secular.

\footnotetext{
19 Dados do EVS para 2008.

${ }^{20}$ Cf. Pordata, "Forma de celebração do casamento".

${ }^{21}$ Cf. Štatistický úrad SR, KBS, ECAV.

22 Cf. Instytut Statystyki Kościoła Katolickiego za 2016 rok.
} 
Outros exemplos da manutenção do discurso ou habitus religioso (Bourdieu, 1998), citando neste contexto apenas o caso português, são, por exemplo:

a) Fátima e o aumento do turismo religioso, nomeadamente o crescimento do número de peregrinos (nacionais e estrangeiros) em celebrações oficiais do santuário e de missas oficiais e particulares, entre os períodos 2005, 2008 e $2017^{23}$.

b) A presença e destaque dado aos dignitários religiosos em cerimónias oficiais públicas, como a abertura do ano judicial, a bênção das fitas dos finalistas universitários ou o início do mais recente mandato presidencial solenizado, em 2016, com uma oração ecuménica na Mesquita Central de Lisboa.

c) A renomeação das freguesias de Lisboa (2011) e a manutenção das designações religiosas, como Santa Maria Maior, Misericórdia ou Santo António ou a nomeação da nova ponte sobre o rio Douro (2018) - Ponte D. António Francisco dos Santos (antigo bispo do Porto).

d) O caso dos feriados civis e religiosos (2012) em que, no contexto da crise financeira, económica e social o Estado português, querendo diminuir o número de feriados no país, decretou o fim dos feriados dos dias do Corpo de Deus e de Todos os Santos. No entanto, por pressão social e da Santa Sé, eles foram apenas suspensos temporariamente, tendo sido repostos em 2016.

e) A parceria social estratégica na área da solidariedade social entre o Estado e as igrejas e comunidades religiosas (através do financiamento público da últimas). Lembremos, por exemplo, o plano de emergência social estabelecido entre a Câmara Municipal e o Patriarcado do Porto (2013) ou o prémio dos direitos humanos, oferecido pela Assembleia da República, e que entre 2010 e 2012 (um dos períodos mais agudos da crise) apenas distinguiu organizações de matriz religiosa (católica) ou lideradas por um dos seus membros.

O erro de Berger foi, como o próprio admite (Berger 2014: ix-x), ter compreendido a diversidade apenas como um fator que sustentava a secularização, não entendendo que, mesmo em circunstâncias de multiplicidade de escolhas cognitivas e normativas, muitas dessas opções continuam a ser religiosas, como vimos nos vários exemplos citados.

Berger procura resolver o velho problema das teorias da secularização, não assumindo uma correlação inevitável entre as condições constituidoras da modernidade e os processos da secularização. Deste modo, a modernização deixa, inevitavelmente, de produzir a secularização e o perecimento definitivo

\footnotetext{
${ }^{23}$ Cf. Santuário de Fátima, "Dados estatísticos".
} 
da religião. Entre o eixo tradicional modernização-religião, o autor coloca um novo elemento modernização-diversidade-religião. Como vimos, na nova concepção bergeriana a modernidade leva inelutavelmente à diversidade. Todavia, esta última provoca a tal contaminação cognitiva através da qual as pessoas, com diferentes cosmovisões, se falam e influenciam de forma permanente. De acordo com Berger (2014: 15), isso tem duas consequências essenciais: fundamentalismo ou relativização. O primeiro balcaniza a sociedade, conduzindo a situações de coerção ou conflito permanente; o segundo, muito devedor da linha tradicional bergeriana, enfraquece o consenso moral sobre o qual as sociedades não sobrevivem. Embora seja da opinião de que o problema da diversidade terá de ser encontrado com um meio-termo entre as duas proposições, Berger parece entender que, em condições de maior diversidade, a segunda proposição tende a ser dominante. De acordo com o argumento, a diversidade "provoca uma situação em que a relativização se torna numa experiência perene" e, com isso, as certezas inquestionáveis passam a ser uma "mercadoria escassa" (Berger 2014: 9).

Assim sendo, se a modernização provoca a diversidade e se a diversidade relativiza e enfraquece as certezas adquiridas, privando a religião da sua condição inquestionável, a diversidade fomentará, irremediavelmente, a secularidade. Como o próprio Berger continua a admitir, os processos da modernidade (sobretudo as migrações, a urbanização, educação e os média digitais) enfraquecem o religioso, pelo facto de o expulsarem de grande parte da ordem institucional. Ora, se a modernidade conduz à diversidade e se a diversidade relativiza as certezas religiosas, a consequência derradeira é que a modernidade, por intermédio da diversidade, é acompanhada dum enfraquecimento do religioso. Esta proposta é, mesmo com as revisões de Berger e com o seu pedido de substituição do paradigma da secularização pelo da diversidade, o cerne de qualquer teoria da secularização.

Talvez por isso, ainda hoje, Bruce (2017) e outros autores resistentes às críticas à teoria da secularização (Pickel 2017) consigam concordar com Berger, porque em ambos a diversidade diminui a plausibilidade dos compromissos religiosos, através da redução ou relativização da certeza sobre crenças e argumentos religiosos. Isto significa que a modernidade produziu uma estrutura secular, imanente na concepção tayloriana, que permite aos indivíduos lidar com muitas áreas da vida sem qualquer referência ao religioso. Como nos diz Ammerman (2014), na sua resposta a Berger, quando este quadro secular/ imanente se torna dominante, como sugere a nova concepção bergeriana, e os indivíduos deixam de ter locais de interação religiosa regular - onde o discurso religioso pudesse ser preponderante - é normal que isso molde a sua maneira de estar no mundo. Ou seja, as pessoas deixam de conseguir "falar sobre uma - ou talvez mesmo ver uma - camada de realidade espiritual" quando interagem no seu quotidiano (Ammerman 2014: 196). 
Como pudemos analisar, especialmente com a análise do trabalho mais recente de Berger, as diferentes teses que tentam entender os impactos da diversidade na religião têm tanto de complexo como de aparentemente contraditório. Em suma, embora pareça contraproducente apoiar as teorias da secularização, nomeadamente em face da diversidade das sociedades modernas e da força da religiosidade dentro delas, também parece implausível continuar a negar a evolução dum quadro imanente que, no esforço de gestão dessa pluralidade e vitalidade, é relativamente neutro ou hostil para com a religião.

\section{Considerações finais}

Num comentário final, pesando o que aqui foi analisado, podemos dizer que, considerando o conjunto de países e o período temporal selecionados, a teoria que assevera que a diversidade apenas provoca a deslocação e recomposição do religioso e não o seu declínio parece ter uma sustentação teórica bastante frágil. Verificámos que a religião, tal como Berger (2014) admitiu, não está imune às consequências da diversidade, sendo, aliás, um dos seus maiores desafios contemporâneos. Não é portanto de excluir a hipótese de que isto suceda por conta do sexteto de razões prévia e implicitamente examinadas e que agora explicitamos:

a) O gradual predomínio dum viés iluminista - assume um afastamento da religião do espaço público.

b) $\mathrm{O}$ estabelecimento de sistemas de secularismo (moderado) implementa processos de regulação/controlo do religioso, baseados em princípios de neutralidade secular.

c) O desenvolvimento e hegemonia de culturas de secularidade reclamam a primazia da autoridade política, racional e secular.

d) A diminuição dos níveis de literacia religiosa e do papel do religioso nas práticas quotidianas dos indivíduos - um espaço público que passa a viver maioritariamente de referências imanentes.

e) A mais difícil acessibilidade às províncias de significado finito e a diminuição das confirmações transcendentes face-a-face - o que torna a vida quotidiana menos suscetível à influência da religião.

f) A contaminação cognitiva e o efeito fragilizador e relativizador da própria diversidade - há uma relativização das certezas incontestáveis que conduz ao enfraquecimento do consenso religioso. 
No entanto, este sexteto de asserções e as construções teóricas que as acompanham, não são sinónimos dum perecimento da religião, sendo ainda menos tributários da ideia de que isso sucederá duma forma universal, unilinear ou determinista. Concordados com a asserção de Berger que diz que, não obstante a existência dalguns efeitos secularizantes (nomeadamente da emergência e predomínio dum paradigma imanente de interpretação do mundo), a modernidade/diversidade tem consequências limitadas no religioso. Além disso, a própria religião mantém a sua influência, sendo por vezes capaz de a reforçar. Como sublinhámos, nos casos referentes à manutenção e adaptação do discurso religioso ou até no caso dos batizados ou dos matrimónios religiosos, a própria cultura de secularidade é igualmente forçada a adaptar-se ao religioso. Há, em certo sentido, uma complementaridade indelével entre ambas, usando uma expressão bergeriana; uma contaminação recíproca, permanente, feita de avanços e recuos, entradas e saídas, marcada por um hibridismo que mistura o sagrado e o secular, como nos disse Ammerman.

Assim sendo, quer concordemos mais ou menos com os argumentos clássicos de Berger, Luckmann ou Luhmann, com os contemporâneos de Bruce ou Pickel, com os retratados de Berger ou com os do quase unânime Taylor relativamente à fragilização da religião pela diversidade, a verdade é que, atualmente, estes são alguns dos esforços científicos mais completos para se compreender o binómio religião-diversidade. Com efeito, neste artigo a nossa intenção não foi propriamente concordar ou discordar com os seus argumentos. Quisemos sobretudo encontrar uma forma de enquadrar teórica e geograficamente esta nova dinâmica das sociedades modernas ocidentais.

Não queremos diminuir a relevância do trabalho por nós desenvolvido, até porque, modéstia à parte, consideramo-lo profícuo para enquadrar e desafiar as teorias clássicas e modernas da secularização e para lançar novas pistas de investigação na área. Todavia, sabemos que serão necessários mais estudos, nomeadamente empíricos, para se sustentar e robustecer esta nova narrativa relativa ao lugar do religioso em condições de diversidade hodierna ou, eventualmente, para falsificá-la. Sabemos que serão imprescindíveis mais investigações, provavelmente com maior amplitude e abrangência, envolvendo naturalmente mais recursos (humanos, temporais e financeiros), que considerem novas áreas geográficas e períodos de análise mais amplos. Contudo, neste momento, apenas podemos esperar que este artigo seja um contributo nesse sentido. 


\section{Bibliografia:}

Ammerman, Nancy T., "Response by Nancy Ammerman: Modern altars in everyday life" pp. 94-110, em Berger, Peter L. (aut.), The Many Altars of Modernity: Toward a Paradigm for Religion in a Pluralist Age, Boston/ Berlim: De Gruyter, 2014.

Berger, Peter, The Sacred Canopy: Elements of a sociological theory of religion, Nova Iorque, Anchor Books, 1990 [1967].

, The Heretical Imperative: Contemporary possibilities of religious affirmation, Norwell: Anchor Press, 1979.

, “An interview with Peter Berger", Hedgehog Review, 8, 2006, pp. 152-162.

, The Many Altars of Modernity: Toward a Paradigm for Religion in a Pluralist Age, Boston/Berlim: De Gruyter, 2014.

; Luckmann, Thomas, The Social Construction of Reality: A Treatise in the Sociology of Knowledge, Londres: Penguin Books, 1966.

Bruce, Steve, God is Dead: Secularization in the West, Cornwall: Blackwell Publishing, 2002.

, "Secularization and the impotence of individualized religion", The Hedgehog Review, 8, 1-2, 2006, pp. 35-45.

, Secularization: In Defence of an Unfashionable Theory, Oxford: UP Oxford, 2011.

, "History, sociology, and secularization" pp. 190-213, em Hartney, Christopher (ed.), Secularisation: New Historical Perspectives, Cambridge: Cambridge Scholars Publishing, 2014.

, "Secularization elsewhere: it is more complicated than that", Politica \& Sociedade, 16, 36, 2017, pp. 195-211.

, "Secularization: From Sacred Canopies to Golf Umbrellas" pp. 103118, em Hjelm, Titus (ed.), Peter L. Berger and the Sociology of Religion 50 Years after The Sacred Canopy, Londres: Bloomsbury Academic, 2018.

Casanova, José, "Reconsiderar la Secularización: Una perspectiva comparada mundial", Revista Académica de Relaciones Internacionales, 7, 2007, pp. $1-20$.

Chaves, Mark; Gorski, Philip, "Religious pluralism and religious participation", Annual Review of Sociology, 27, 2001, pp. 261-281.

Dix, Steffen, "A visibilidade e a invisibilidade das pessoas «sem religião» na sociedade portuguesa", Didaskalia, 43, 1-2, 2013, pp. 57-80. 
Doktór, Tadeusz, "Religious pluralism and dimensions of religiosity: evidence from the project Religious and Moral Pluralism (RAMP)" pp. 25-34, em Pickel, Gert; Müller, Olaf, Church and Religion in Contemporary Europe: Results from Empirical and Comparative Research, Wiesbaden: VS Verlag, 2009.

Eco, Umberto, Cinco Escritos Morais, $6^{\mathrm{a}}$ ed., Rio de Janeiro/São Paulo: Record, 2002.

Graham, Elaine, Apologetics without Apology: Speaking of God in a World Troubled by Religion, Eugene: Cascade Books, 2017.

Luckmann, Thomas, The Invisible Religion: The problem of religion in modern society, Nova Iorque, Macmillan, 1967.

Luhmann, Niklas, A Systems Theory of Religion (Cultural Memory in the Present), André Kieserling (ed.), Stanford: Stanford University Press, 2013 [1998].

Martin, David, On Secularization: Toward a Revised General Theory, Burlington, Vt.: Ashgate, 2005.

,Secularisation, Pentecostalism and Violence: Receptions, Rediscoveries and Rebuttals in the Sociology of Religion, Londres: Routledge, 2017.

McCaffree, Kevin, The Secular Landscape: The Decline of Religion in America, Indiana: Palgrave Macmillan 2017.

Moniz, Jorge Botelho, “As falácias da secularização: análise das cinco críticastipo às teorias da secularização", Política \& Sociedade, 36, 16, 2017, pp. 74-96.

Norris, Pippa; Inglehart, Ronald, Sacred and Secular: Religion and Politics Worldwide, Cambridge: Cambridge University Press, 2004.

Pace, Enzo, Religion as Communication: God's Talk, Londres: Routledge, 2016.

, "Systems theory and religion", Civitas, 17, 2, 2017, pp. 345-359.

Pew Research Center, "The Future of World Religions: Population Growth Projections, 2010-2050 Why Muslims Are Rising Fastest and the Unaffiliated Are Shrinking as a Share of the World's Population", 2015. Disponível em: http://www.pewforum.org/2015/04/02/religiousprojections-2010-2050/. Último acesso a 07.12.2018.

, "The Changing Global Religious Landscape", 2017. Disponível em: http://www.pewforum.org/2017/04/05/the-changing-global-religiouslandscape/. Último acesso a 07.12.2018.

Pickel, Gert, "Secularization - an empirically consolidated narrative in the face of an increasing influence of religion on politics", Politica \& Sociedade, 36, 16, 2017, pp. 259-294. 
Pollack, Detlef, "Response by Detlef Pollack: Toward a new paradigm for the sociology of religion?" pp. 111-122, em Berger, Peter L. (aut.), The Many Altars of Modernity: Toward a Paradigm for Religion in a Pluralist Age, Boston/Berlim: De Gruyter, 2014.

; Pickel, Gert, "Church-State relations and the vitality of religion in European comparison” pp. 145-166, em Pickel, Gert; Müller, Olaf (eds.), Church and Religion in Contemporary Europe. Results from Empirical and Comparative Research. Wiesbaden: Springer-Verlag, 2009.

, Religion and Modernity: An International Comparison, Oxford: Oxford University Press, 2017.

Quack, Johannes; Schuh, Cora (eds.), Religious Indifference New Perspectives From Studies on Secularization and Nonreligion, Wiesbaden: Springer, 2017.

Stolz, Jörg, "A Silent Battle. Theorizing the effects of competition between churches and secular institutions", Review of Religious Research, 51, 3, 2010, pp. 253-276.

Taylor, Charles, A Secular Age, Cambridge: Harvard University Press, 2007.

Teixeira, Alfredo (org.), Identidades Religiosas em Portugal: Ensaio interdisciplinar, Lisboa: Paulinas Editora, 2012.

Vilaça, Helena, Da Torre de Babel às Terras Prometidas - Pluralismo Religioso em Portugal, Porto: Edições Afrontamento, 2006.

et. al., The Changing Soul of Europe Religions and Migrations in Northern and Southern Europe, Londres: Routledge, 2014.

Voas, David; Olson, Daniel; Crockett, Alasdair, "Religious pluralism and participation: Why previous research is wrong", American Sociological Review, 67, 2, 2002, pp. 212-230.

Wilson, Bryan, Religion in Secular Society: A sociological comment, Harmondsworth, Penguin Books, 1969 [1966].

Wohlrab-Sahr, Monika; Burchardt, Marian, "Revisitando o secular: secularidades múltiplas e trajetórias para a modernidade", Política \& Sociedade, 16, 36, 2017, pp. 143-173.

Woodhead, Linda, "Introduction" pp. 1-33, em Woodhead, Linda; Catto, Rebecca (eds.), Religion and Change in Modern Britain, Oxon: Routledge, 2012. 